\title{
Diabetes and the enteric nervous system
}

\author{
B. CHANDRASEKHARAN and S. SRINIVASAN \\ Division of Digestive Diseases, Emory University, Atlanta, GA, USA
}

\begin{abstract}
Diabetes is associated with several changes in gastrointestinal (GI) motility and associated symptoms such as nausea, bloating, abdominal pain, diarrhoea and constipation. The pathogenesis of altered GI functions in diabetes is multifactorial and the role of the enteric nervous system (ENS) in this respect has gained significant importance. In this review, we summarize the research carried out on diabetes-related changes in the ENS. Changes in the inhibitory and excitatory enteric neurons are described highlighting the role of loss of inhibitory neurons in early diabetic enteric neuropathy. The functional consequences of these neuronal changes result in altered gastric emptying, diarrhoea or constipation. Diabetes can also affect GI motility through changes in intestinal smooth muscle or alterations in extrinsic neuronal control. Hyperglycaemia and oxidative stress play an important role in the pathophysiology of these ENS changes. Antioxidants to prevent or treat diabetic GI motility problems have therapeutic potential. Recent research on the nerve-immune interactions demonstrates inflammation-associated neurodegeneration which can lead to motility related problems in diabetes.
\end{abstract}

\section{Keywords}

diabetes; enteric nervous system; gastric emptying; motility; neuronal nitric oxide synthase; neuropeptides

\section{INTRODUCTION}

Diabetes is associated with gastrointestinal (GI) symptoms such as nausea, bloating, abdominal pain, diarrhoea, constipation and delayed gastric emptying (GE). ${ }^{1} \mathrm{Up}$ to $75 \%$ of patients with diabetes can experience these symptoms. The pathogenesis of altered GI functions in diabetes is still under research and the role of enteric nervous system (ENS) and its neurotransmitters has gained significance over the past years. The ENS is an autonomous entity that controls and coordinates motility, blood flow and secretion in the GI tract. ENS is present throughout the entire GI tract, the biliary tract and the pancreas. The ENS is comprised approximately $10^{8}$ sensory, motor and inter neurons, present in two major plexus, the myenteric and submucusal plexus. These neurons control intestinal motility and secretion by initiating reflexes in response to the luminal contents and smooth muscle tension. ${ }^{2}$ The ENS is connected to the brain by both afferent and efferent pathways. The former is the basis not only for sensation of gut origin, particularly pain but also other sensations such as fullness, bloating, and nausea. Efferent pathways provide the parasympathetic and sympathetic innervation that helps to coordinate the different regions of the GI tract with their specialized functions.

Address for correspondence: Shanthi Srinivasan, MD, Division of Digestive Diseases, Emory University, Whitehead Research Building, Suite 246, 615 Michael Street, Atlanta, GA 30322, USA. Tel: +1 404727 5298; fax: +1 404712 2980; ssrini2@emory.edu. 
In this review, we highlight the changes in inhibitory and excitatory neurons in early and late diabetes and the changes in GI motility in human and animal models of diabetes. The mechanism of changes in motility involving neuronal loss, oxidative stress, advanced glycation end products (AGEs) and apoptosis are elaborated. Changes in smooth muscle and afferent and efferent signalling to the GI tract are also seen in diabetes. Antioxidants and nerve growth factors have a potential to treat motility related problems in diabetes. Nerveimmune interactions, involving modulation of inflammation associated neurodegeneration can lead to GI motility problems in diabetes.

\section{DIABETES AND NEURONAL DEGENERATION}

\section{Changes in neuron number/size in the GI tract}

Diabetes is associated with changes in enteric neuronal size, number and neurodegenerative changes such as axonal swelling (Table 1). These findings are mainly derived from whole mounts of myenteric plexi of different regions of the GI tract. The studies cited in Table 1 have been carried out in rat models and streptozotocin (STZ) (45-200 mg kg-1 body weight) has been used for induction of diabetes. A marked degeneration of axon plasma membrane in the myenteric plexi ganglia at 2 weeks of diabetes in rats, followed by axon sprouting and regeneration at 6 weeks has been observed. ${ }^{3}$ Reduction in neurons is also seen in the stomach, ${ }^{4}$ cecum, ${ }^{5}$ ileum ${ }^{6}$ and proximal colon. ${ }^{7}$ In dorsal root ganglion the neurons of larger diameter ( $250 \mu \mathrm{mol} \mathrm{L}^{-1}$ ) are more susceptible to injury compared to smaller neurons. ${ }^{8}$ However, few studies have reported an increase in NADPH Diaphorase cell body area in the ileum whole mounts after 16 weeks of diabetes. ${ }^{9}$ These findings suggest that there are two phases of neuronal changes in diabetes -an initial phase of loss of neurons and a later phase with possible regeneration.

\section{Diabetes and alterations in chemical coding of neurons in the GI tract}

The different neurotransmitters expressed by a neuron determine its chemical code. Several animal studies have described altered chemical coding in diabetes. Enteric neuronal subpopulations respond differently to diabetes, some exhibit degeneration, some undergo change in neurotransmitter content without degeneration while some are unaffected. It is interesting to note that nerves that contain the same neurotransmitter but innervating a specific region of GI tract are also differentially affected. The neuronal remodelling affects the ratio of inhibitory and contractile neurons, which in turn leads to impaired nervemediated muscle responses and can contribute to the motility dysfunction seen in diabetes. Data suggest that inhibitory neurons [neuronal nitric oxide synthase (nNOS), vasoactive intestinal peptide (VIP) and neuropeptide Y (NPY)] and galanin neurons are more severely affected compared with excitatory neurons [choline acetyl transferase (ChAT) and Substance P (SP)].

\section{Loss of inhibitory neurons in diabetes}

The nNOS neurons have been studied to a great extent in diabetes-related GI motility dysfunction. The nitric oxide (NO) produced by these neurons, is a major nor-adrenergic, norcholinergic (NANC) inhibitory neurotransmitter which mediates the smooth muscle relaxation in the GI tract and is therefore important in gut motility. ${ }^{11}$ Several studies have demonstrated loss of nNOS neurons in diabetes. Loss of nitrergic function in the stomach can result in delayed GE or changes in accommodation. ${ }^{12}$ The loss of nitrergic function in the stomach of STZ-mice and non-obese diabetic (NOD) mice was restored by insulin therapy. ${ }^{13}$ A reduction in nNOS expression was also observed in the antral myenteric plexus of STZ diabetic rats at 3 months ${ }^{14}$ and the spontaneously diabetic BB/W rat at 6 months of diabetes. ${ }^{15}$ A loss of ileal myenteric NADPH diaphorase-stained neurons at 8 weeks of diabetes in mice has been demonstrated. ${ }^{16}$ In the initial phase of diabetes, there is a loss of 
nNOS content and function, however, at later stages there is nitrergic degeneration with complete loss of nitrergic function. ${ }^{17}$ Full thickness jejunal sections from a diabetic patient showed a reduction in nNOS neurons and the interstitial cells of Cajal (ICC). ${ }^{18}$ A reduction in ICC and nNOS neurons in patients with diabetes (type II) proportional to the severity of diabetes was observed as compared to controls. ${ }^{19}$ The susceptibility of nitrergic neurons in the GI tract appears to be regional with the stomach and proximal intestine being affected first and the distal colon being the last to be affected. Within the stomach, the neurons along the lesser curvature are more affected compared with the greater curvature. ${ }^{4}$ The mechanism of loss of nNOS neurons could be secondary to increased apoptosis. ${ }^{16,17}$

In later stages of diabetes, there appears to be an increase in nitrergic neurons. ${ }^{9,20}$ This is probably secondary to regeneration due to early loss of nNOS neurons. An increase in nNOS in the myenteric plexi of duodenum ${ }^{21}$ and ileum ${ }^{9}$ at 32 weeks of diabetes has been observed. A subset of nNOS neurons lacking of heme oxygenase 2 were more susceptible to the changes of diabetes. ${ }^{22}$ Overall, diabetes seems to be associated with a reduction in nNOS neurons with a possible regenerative response at later stages. These changes can contribute to the motility disturbances in diabetes.

VIP together with NO comprises the primary inhibitory NANC neurotransmitters. A decrease in VIP neurons at 4 weeks of diabetes has been reported ${ }^{23,24}$ Full thickness jejunal biopsies from a patient have also shown a decrease in neurons in type I diabetes. ${ }^{18}$ Overall, the changes in VIP appear to be a decrease in early diabetes and an increase ${ }^{25}$ in advanced diabetes similar to nNOS neurons. NPY, another inhibitory neurotransmitter, present predominantly in NANC neurons, often co-localizes with nNOS. ${ }^{26}$ Increase in NPY immunoreactivity in duodenum, colon and ileum has been reported in rats. ${ }^{25,27}$ Obese diabetic mice also show increased NPY in the colon. ${ }^{28}$ The concentration of galanin, another inhibitory peptide, was reduced in the colon of obese diabetic mice. ${ }^{23}$ However, an increase in galanin was observed in colon of NOD mice ${ }^{29}$ and ileum of 12-week-old diabetic rats. ${ }^{30}$ In summary, the inhibitory neurotransmitters nNOS, VIP and galanin appear to decrease in early diabetes with an increase in later stages of diabetes, possibly secondary to regeneration. On the other hand, NPY seems to increase early in diabetes and this may be a compensatory response to loss of other inhibitory neurons.

\section{Increase in excitatory neurons in diabetes}

Choline acetyl transferase is specific to excitatory neurons, and it is the enzyme that hydrolyzes the neurotransmitter acetyl choline, produced by cholinergic nerves. The acetyl choline released by these nerves mediate the contractile responses of the GI tract. The density of cholinergic innervation has been reported to increase in diabetes in the jejunum, ileum (myenteric plexi) and muscularis propria of duodenum from rats and non-obese mice. $3,31,32$ This increase may account for increased contractility in diabetes. Serotonin is an important neurotransmitter of the gut responsible for mediating the fasting phase III contractions of migrating motor complex (MMC) or postprandial contractions, which are commonly impaired in diabetes. A reduction in serotonin content of the antrum and duodenum has been noted in the diabetic animals. ${ }^{33,34} \mathrm{An}$ increase in serotonin content in colon has also been reported. ${ }^{35}$ Changes in serotonin receptor expression may mediate the sensory component of GI disturbances seen in diabetes such as nausea and early satiety.

\section{Reduction in sensory neuropeptides in diabetes}

Calcitonin gene-related peptide (CGRP), a sensory 37-amino acid peptide, is co-localized with SP, ${ }^{36}$ a member of the tachykinin super family. In the myenteric and submucosal plexus of rat ileum and colon, CGRP-like immunoreactivity was found to be significantly reduced after 8 weeks of diabetes. ${ }^{30,31} \mathrm{SP}$ is a 11-aminoacid polypeptide involved in the 
transmission of pain impulses from the periphery to the central nervous system (CNS). Decrease in SP in stomach and ileum of rats at varied durations of 5-44 weeks of diabetes has also been reported. Although some studies demonstrate an increase in SP, ${ }^{18,27}$ a majority of studies support a reduction in SP in diabetes. ${ }^{37,38}$ Recent findings indicate that autoimmune attack on $\beta$-cells as in diabetes type I appears to be triggered by abnormal sensory nerves that lack SP. ${ }^{39}$ Studies on NOD mice revealed that their sensory neurons did not produce enough SP. When these mice were given an injection of SP directly into the pancreas, insulin and glucose levels returned to normal. Based on these recent findings, it appears that exogenous SP can reverse insulin dependent diabetes mellitus (IDDM). More studies on SP might help to explain and attenuate the complications in type II diabetes. The studies on neurochemical coding in diabetes have been summarized in Table 2.

\section{GASTRIC MOTILITY IN DIABETES}

GI motility disorders are very commonly associated with diabetes. Of the various abnormalities, gastroparesis is one of the most common motility disturbances related to autonomic and peripheral neuropathy. GE has been shown to be delayed in animal models of diabetes ${ }^{13}$ and in patients with diabetes ${ }^{40}$ and correlates with the severity of diabetes. Electrical field stimulation (EFS) of intestinal muscle strips allows us to study the effect of diabetes on the functional loss or gain of inhibitory or excitatory enteric neurons. Several studies have examined the responsiveness of stomach, intestine and colonic tissues from diabetic animals in vitro. Diabetes impairs NANC relaxation in rodents. ${ }^{16,41}$

\section{MECHANISMS UNDERLYING DIABETIC ENTERIC NEUROPATHY}

\section{Apoptosis}

Apoptosis can contribute to the enteric neuronal loss and disorders in GI motility in diabetes. An increase in apoptosis was reported in acutely dissociated dorsal root ganglionic (DRG) neurons from 3- to 6-week-old diabetic rats. ${ }^{42} \mathrm{~A}$ similar increase in apoptosis in vitro of rat embryonic enteric neuronal cultures when treated with 20 and $40 \mathrm{mmol} \mathrm{L}^{-1}$ glucose, and increased apoptosis in diabetic mice has been reported. ${ }^{16}$ Increased caspase- 3 and TUNEL positive cells in the myenteric plexi of 4- to 8-week diabetic rats have been demonstrated. ${ }^{43,44}$ The presence of a calcium channel stimulating auto antibody has been found in type I diabetic patients and this is associated with disrupted intestinal motility. ${ }^{45}$ Serum from diabetics induced apoptosis in dorsal root ganglion neurons in culture. ${ }^{46}$

\section{Oxidative stress}

Oxidative stress, in which production of highly reactive oxygen species (ROS) and reactive nitrogen species (RNS) overwhelms antioxidant defences, is a feature of many neurological diseases and neurodegeneration. Moreover, oxidative stress also activates mechanisms that result in a glia-mediated inflammation that also causes secondary neuronal damage. Studies have examined the lipid peroxidation profiles in heart, liver, kidney and retina of diabetic animals. However, there are only a few studies specifically related to the oxidative stress in the GI tract. Increased activities of glutathione-S-transferase (GST) have been reported in jejunum and ileum of 6 weeks diabetic rats. ${ }^{47}$ Similar observation has been made at 6 weeks of diabetes in rats where catalase, superoxide dismutase (SOD), malondialdehyde and protein carbonyl content were increased, and glutathione peroxidase was decreased. ${ }^{48}$ Recent research on oxidative stress in diabetes has identified that different populations of sympathetic neurons differ in their susceptibility to neuropathy, which in turn is due to an increased vulnerability to oxidative stress. ${ }^{49}$ This indicates that molecular differences between the sympathetic ganglia may be responsible for their differential response to diabetes. Analysis of global gene expression patterns in ganglia from control and diabetic rats has revealed marked differences in gene expression in celiac/superior mesenteric 
ganglion and superior cervical ganglion neurons under control conditions and in response to diabetes. ${ }^{50}$ Future studies need to be carried out to assess oxidative stress and gene expression profiles in diabetes in enteric neuronal ganglia.

\section{Advanced glycation end product and their receptors}

AGE and the receptor for AGEs (RAGE) are expressed in peripheral neurons. They have been identified to play a significant role in diabetic neuropathy. High intracellular glucose concentration can trigger protein glycation via increased formation of methyl glyoxal, glyoxal and 3-deoxyglucosones. RAGE-induced phosphatidylinositol-3 kinase activity has also been attributed to the formation of ROS, caspase- 3 activation, and nuclear DNA degradation..$^{51}$ In vitro studies on the whole mount preparations of longitudinal muscles with adherent myenteric plexus from the duodenum of adult male rats exposed to glycated bovine serum albumin (AGE-BSA) or BSA for $24 \mathrm{~h}$ indicate a decrease in nNOS expression. ${ }^{52}$

\section{Nerve growth factors, antioxidants and diabetes}

Loss of neurofilaments in myelinated sensory axons, and neurofilament numbers in unmyelinated fibres has been observed at 6 months of diabetes. ${ }^{53}$ The administration of growth factors, hormones and antioxidants can modulate diabetic neuropathy. Insulin, nerve growth factors and antioxidants such as $a$-lipoic acid and glutathione have been extensively studied. Insulin like growth factor-1 (IGF-1) and neurotrophin-3 (NT-3) can reverse experimental diabetic neuropathy. ${ }^{54}$ Hedgehog proteins known to modulate the development of the ENS can restore diabetes induced changes in motor and sensory neuropathy. ${ }^{55}$ Increased oxidative stress is considered to be a causal factor in the development of diabetic neuropathy. The protective effects of antioxidants like lipoic acid and evening primrose oil on diabetes-induced enteric nerve degeneration in the ileum have been identified. ${ }^{56}$

\section{Alteration in intestinal muscle contractility}

An increase in intestinal smooth muscle mass ${ }^{57}$ and increased muscle contractility ${ }^{58}$ has been reported in diabetes. A reduction in muscarinic receptors and activation of voltage gated calcium channels in diabetes can also lead to impairment in smooth muscle contractility. ${ }^{58,59}$ Altered signalling through the protein kinase $\mathrm{C}$ pathway in gastric myocytes may also contribute to diabetic gastroparesis.$^{60}$ Insulin can regulate the altered neuronal M2 muscarinic receptor function seen in the ileum of diabetic rats. ${ }^{61}$ Recent studies have demonstrated that myopathy may play a role in diabetic gastroparesis. A reduction in insulin/IGF-I signalling in diabetes causes ICC depletion, subsequent stem cell factor depletion and resultant smooth-muscle atrophy. ${ }^{62}$

\section{Brain gut interactions in diabetes}

The CNS, mainly the hypothalamus and brain stem along with the ENS help in maintaining glucose homeostasis. The arcuate nucleus in hypothalamus is sensitive to incretin hormones such as GLP-1, ghrelin and CCK as well as glucose and fatty acids. Vagal nerve dysfunction as evidence by a reduced response to sham feeding-induced serum pancreatic polypeptide and ghrelin is seen in patients with diabetic gastroparesis. ${ }^{63}$ Vagally mediated duodenal bicarbonate secretion was impaired at 6 weeks of diabetes in STZ-diabetic rats. ${ }^{64}$ The major viscerosensory information provided by afferent fibres is processed in the nucleus of tractus solitarius of the brain stem. The afferent and efferent innervation of the GI tract is adversely affected in diabetes. Impaired afferent vagal functions have been demonstrated in patients with diabetic gastroparesis. ${ }^{65}$ Increased sensory threshold in the rectal mucosa of patients with diabetes has been demonstrated and this may contribute to fecal incontinence. ${ }^{66}$ Both myelinated and unmyelinated fibres in vagus nerve of the diabetic BB rat have been shown to be decreased in size. ${ }^{67}$ Changes in sympathetic pre- and postganglionic fibres including a 
reduction in cytoplasmic area, axonal dwindling have been noted 1 year after the induction of diabetes in rodent models. ${ }^{68}$ Sympathetic neuronal dystrophy with accumulation of neurofilaments and mitochondria has been noted in the experimental models of diabetes. ${ }^{69}$ Thus in addition to the changes in the ENS in diabetes, significant changes are also present in the vagus and sympathetic innervation of the GI tract.

\section{Models to study diabetes-induced changes in the GI tract}

Current models to study diabetes-induced changes in the GI tract include chemically induced diabetes in rodents and genetic mouse models. A few studies have focused on diabetes induced changes in the ENS using human gastrectomy samples. ${ }^{19}$ In vitro studies on the effect of hyperglycaemia on primary enteric neurons have been limited due to the difficulty in establishing long-term neuronal cultures. Development of enteric neuronal cell lines can provide a useful tool to assess the changes of hyperglycaemia in cultures. The use of primary enteric neuronal cell line in co-culture with support cells like enteric glia can also help us understand the role of enteric glia in modulating diabetic enteric neuropathy. The studies on estimation of ganglion size in diabetes would be more accurate with the use of 3D image analysis of ganglia. Also, laser capture micro dissection of enteric ganglia in control and diabetic rodent and human samples can provide us useful information on the mechanism of diabetic enteric neuropathy. The current method of evaluating changes in chemical coding secondary to diabetes is immunohistochemical staining of whole mount and cross section of rodent and human intestines. Future studies are needed to standardize the chemical coding changes in diabetes, by focusing on a few inhibitory and excitatory neurotransmitters including co-localization of specific neuropeptides, in specific regions of the GI tract and functional correlation of these changes through EFS induced intestinal muscle strip contraction and relaxation.

\section{FUTURE PERSPECTIVES IN DIABETES-RELATED ENS RESEARCH}

\section{Nerve-immune interactions}

The evidence that neurons can regulate the activity of immune cells has led to the concept of 'neurogenic inflammation'. Neuropeptide synthesis occurs not only in enteric nerves, but also in immune cells of the gut associated lymphoid tissue (GALT). Lymphocytes express receptors for most of these neuropeptides, but other immune cells, such as macrophages and mast cells, are capable of responding to these ENS products.

In type I diabetes, it is now understood that neuropeptides can regulate the immune cell activity which regulates $\beta$-cell survival. Recent study indicated that defect in a subset of sensory neurons innervating the pancreas plays a major role in initiating the chain of events that will lead to local inflammation, islet destruction, and autoimmune diabetes. ${ }^{39,70}$ The neuropeptides by acting as immune modulators can stimulate pro-inflammatory cytokine production and result in neurodegeneration. Few neuropeptides have been reported to modulate immune cell function like NPY,${ }^{71} \mathrm{CGRP}^{72}$ and VIP. ${ }^{73}$ Thus there is an intimate and delicate relationship between neuropeptide and cytokine production, and further studies in this field are required to address the gene regulatory processes underlying neuropeptidecytokine interactions in diabetic enteric neuropathy.

\section{SUMMARY}

Diabetes is associated with a remodelling of the ENS encompassing modifications in enteric neuronal morphology, neuromediator content and changes in the function of enteric neurons. These changes in enteric neurons are likely to play a role in alterations in motility and secretory functions of the GI tract. A marked change in specific enteric neuropeptides likes NPY, nNOS, VIP, CGRP, ChAT and SP is observed in the ENS in experimental models of 
diabetes. This disturbs the critical balance between the inhibitory and excitatory neuropeptides in the ENS, the disturbance of this ratio, we believe, leads to disorders in GE and gut motility. In addition the electrophysiological properties of neurons are adversely affected. The studies in humans also indicate a selective loss of neurons in diabetes condition and altered GI motility changes similar to that in animal models. Oxidative stress, advanced glycation end products, neuronal apoptosis and nerve-immune interaction mainly account for the neurodegeneration (Fig. 1). Nerve growth factors and antioxidants can partially attenuate neuronal degeneration by mitigating oxidative stress. Transplantation of intestinal enteric neurons to restore the neuronal loss seen in severe diabetic enteric neuropathy needs to be examined as a potential therapeutic option. Future studies need to examine as to how the enteric neuropeptides regulate genes associated with oxidative stress, apoptosis and cytokine expression at different stages in the development of diabetes. Also, studies on regulation of enteric peptide expression by cytokines can open new avenues in the treatment of diabetes. Further advances in our understanding of the ENS will have important implications for the treatment of diabetes-related gut disorders.

\section{References}

1. Bytzer P, Talley NJ, Leemon M, et al. Prevalence of gastrointestinal symptoms associated with diabetes mellitus: a population-based survey of 15,000 adults. Arch Intern Med. 2001; 161:198996. [PubMed: 11525701]

2. Furness JB, Kunze WA, Clerc N. Nutrient tasting and signaling mechanisms in the gut II. The intestine as a sensory organ: neural, endocrine, and immune responses. Am J Physiol. 1999; 277:G922-8. [PubMed: 10564096]

3. Monckton G, Pehowich E. Autonomic neuropathy in the streptozotocin diabetic rat. Can J Neurol Sci. 1980; 7:135-42. [PubMed: 6447537]

4. Fregonesi CE, de Miranda-Neto MH, Molinari SL, et al. Quantitative study of the myenteric plexus of the stomach of rats with streptozotocin-induced diabetes. Arq Neuropsiquiatr. 2001; 59:50-3. [PubMed: 11299431]

5. Zanoni JN, de Miranda Neto MH, Bazotte RB, et al. Morphological and quantitative analysis of the neurons of the myenteric plexus of the cecum of streptozotocin-induced diabetic rats. Arq Neuropsiquiatr. 1997; 55:696-702. [PubMed: 9629327]

6. Alves AM, Alves EP, Fregonesi CE, et al. Morphoquantitative aspects of NADH-diaphorase myenteric neurons in the ileum of diabetic rats treated with acetyl-L-carnitine. Anat Histol Embryol. 2006; 35:13-8. [PubMed: 16433667]

7. Furlan MM, Molinari SL, Miranda Neto MH. Morpho-quantitative effects of acute diabetes on the myenteric neurons of the proximal colon of adult rats. Arq Neuropsiquiatr. 2002; 60:576-81. [PubMed: 12244395]

8. Kishi M, Tanabe J, Schmelzer JD, et al. Morphometry of dorsal root ganglion in chronic experimental diabetic neuropathy. Diabetes. 2002; 51:819-24. [PubMed: 11872686]

9. Zanoni JN, Buttow NC, Bazotte RB, et al. Evaluation of the population of NADPH-diaphorasestained and myosin- $\mathrm{V}$ myenteric neurons in the ileum of chronically streptozotocin-diabetic rats treated with ascorbic acid. Auton Neurosci. 2003; 104:32-8. [PubMed: 12559201]

10. De Miranda Neto MH, Defani MA, Fregonesi CE, et al. Morphometric and quantitative evaluation of the NADH-diaphorase positive myenteric neurons of the jejunum of streptozotocin-diabetic rats supplemented with acetyl-L-carnitine. Anat Histol Embryol. 2005; 34:154-8. [PubMed: 15929729]

11. Bult H, Boeckxstaens GE, Pelckmans PA, et al. Nitric oxide as an inhibitory non-adrenergic noncholinergic neurotransmitter. Nature. 1990; 345:346-7. [PubMed: 1971425]

12. Takahashi T. Pathophysiological significance of neuronal nitric oxide synthase in the gastrointestinal tract. J Gastroenterol. 2003; 38:421-30. [PubMed: 12768383]

13. Watkins CC, Sawa A, Jaffrey S, et al. Insulin restores neuronal nitric oxide synthase expression and function that is lost in diabetic gastropathy. J Clin Invest. 2000; 106:373-84. [PubMed: 10930440] 
14. Wrzos HF, Cruz A, Polavarapu R, et al. Nitric oxide synthase (NOS) expression in the myenteric plexus of streptozotocin-diabetic rats. Dig Dis Sci. 1997; 42:2106-10. [PubMed: 9365143]

15. Takahashi T, Nakamura K, Itoh $\mathrm{H}$, et al. Impaired expression of nitric oxide synthase in the gastric myenteric plexus of spontaneously diabetic rats. Gastroenterology. 1997; 113:1535-44. [PubMed: 9352855]

16. Anitha M, Gondha C, Sutliff R, et al. GDNF rescues hyperglycemia-induced diabetic enteric neuropathy through activation of the PI3K/Akt pathway. J Clin Invest. 2006; 116:344-56. [PubMed: 16453021]

17. Cellek S, Foxwell NA, Moncada S. Two phases of nitrergic neuropathy in streptozotocin-induced diabetic rats. Diabetes. 2003; 52:2353-62. [PubMed: 12941776]

18. He CL, Soffer EE, Ferris CD, et al. Loss of interstitial cells of cajal and inhibitory innervation in insulin-dependent diabetes. Gastroenterology. 2001; 121:427-34. [PubMed: 11487552]

19. Iwasaki H, Kajimura M, Osawa S, et al. A deficiency of gastric interstitial cells of Cajal accompanied by decreased expression of neuronal nitric oxide synthase and substance $\mathrm{P}$ in patients with type 2 diabetes mellitus. J Gastroenterol. 2006; 41:1076-87. [PubMed: 17160518]

20. Adeghate E, al-Ramadi B, Saleh AM, et al. Increase in neuronal nitric oxide synthase content of the gastroduodenal tract of diabetic rats. Cell Mol Life Sci. 2003; 60:1172-9. [PubMed: 12861383]

21. Furlan MM, de Miranda-Neto MH, de Sant'ana DM, et al. Number and size of myenteric neurons of the duodenum of adult rats with acute diabetes. Arq Neuropsiquiatr. 1999; 57:740-5. [PubMed: 10751907]

22. Shotton HR, Lincoln J. Diabetes only affects nitric oxide synthase-containing myenteric neurons that do not contain heme oxygenase 2. Brain Res. 2006; 1068:248-56. [PubMed: 16375869]

23. El-Salhy M. Neuroendocrine peptides of the gastrointestinal tract of an animal model of human type 2 diabetes mellitus. Acta Diabetol. 1998; 35:194-8. [PubMed: 9934817]

24. Nowak TV, Chey WW, Chang TM, et al. Effect of streptozotocin-induced diabetes mellitus on release of vasoactive intestinal polypeptide from rodent small intestine. Dig Dis Sci. 1995; 40:828-36. [PubMed: 7720477]

25. Eaker EY, Sallustio JE, Marchand SD, et al. Differential increase in neuropeptide Y-like levels and myenteric neuronal staining in diabetic rat intestine. Regul Pept. 1996; 61:77-84. [PubMed: 8701031]

26. Cox HM. Neuropeptide Y receptors; antisecretory control of intestinal epithelial function. Auton Neurosci. 2007; 133:76-85. [PubMed: 17140858]

27. Feher E, Batbayar B, Ver A, et al. Changes of the different neuropeptide-containing nerve fibers and immunocells in the diabetic rat's alimentary tract. Ann N Y Acad Sci. 2006; 1084:280-95. [PubMed: 17151308]

28. Spangeus A, El-Salhy M. Myenteric plexus of obese diabetic mice (an animal model of human type 2 diabetes). Histol Histopathol. 2001; 16:159-65. [PubMed: 11193191]

29. El-Salhy M. Gastrointestinal transit in nonobese diabetic mouse: an animal model of human diabetes type 1. J Diabetes Complicat. 2001; 15:277-84. [PubMed: 11561557]

30. Belai A, Calcutt NA, Carrington AL, et al. Enteric neuropeptides in streptozotocin-diabetic rats; effects of insulin and aldose reductase inhibition. J Auton Nerv Syst. 1996; 58:163-9. [PubMed: 8738309]

31. Spangeus A, Suhr O, El-Salhy M. Diabetic state affects the innervation of gut in an animal model of human type 1 diabetes. Histol Histopathol. 2000; 15:739-44. [PubMed: 10963118]

32. LePard KJ. Choline acetyltransferase and inducible nitric oxide synthase are increased in myenteric plexus of diabetic guinea pig. Auton Neurosci. 2005; 118:12-24. [PubMed: 15795174]

33. Belai A, Lincoln J, Milner P, et al. Progressive changes in adrenergic, serotonergic, and peptidergic nerves in proximal colon of streptozotocin-diabetic rats. Gastroenterology. 1988; 95:1234-41. [PubMed: 2458987]

34. Takahara H, Fujimura M, Taniguchi S, et al. Changes in serotonin levels and 5-HT receptor activity in duodenum of streptozotocin-diabetic rats. Am J Physiol Gastrointest Liver Physiol. 2001; 281:G798-808. [PubMed: 11518692] 
35. Lincoln J, Bokor JT, Crowe R, et al. Myenteric plexus in streptozotocin-treated rats. Neurochemical and histochemical evidence for diabetic neuropathy in the gut. Gastroenterology. 1984; 86:654-61. [PubMed: 6698366]

36. Gibbins IL, Furness JB, Costa M, et al. Co-localization of calcitonin gene-related peptide-like immunoreactivity with substance $\mathrm{P}$ in cutaneous, vascular and visceral sensory neurons of guinea pigs. Neurosci Lett. 1985; 57:125-30. [PubMed: 2412189]

37. Lysy J, Karmeli F, Sestieri M, et al. Decreased substance P content in the rectal mucosa of diabetics with diarrhea and constipation. Metabolism. 1997; 46:730-4. [PubMed: 9225823]

38. Ballmann M, Conlon JM. Changes in the somatostatin, substance $P$ and vasoactive intestinal polypeptide content of the gastrointestinal tract following streptozotocin-induced diabetes in the rat. Diabetologia. 1985; 28:355-8. [PubMed: 2412923]

39. Razavi R, Chan Y, Afifiyan FN, et al. TRPV1+ sensory neurons control beta cell stress and islet inflammation in autoimmune diabetes. Cell. 2006; 127:1123-35. [PubMed: 17174891]

40. Samsom M, Vermeijden JR, Smout AJ, et al. Prevalence of delayed gastric emptying in diabetic patients and relationship to dyspeptic symptoms: a prospective study in unselected diabetic patients. Diabetes Care. 2003; 26:3116-22. [PubMed: 14578248]

41. Jenkinson KM, Reid JJ. Altered non-adrenergic non-cholinergic neurotransmission in gastric fundus from streptozotocin-diabetic rats. Eur J Pharmacol. 2000; 401:251-8. [PubMed: 10924934]

42. Srinivasan S, Stevens M, Wiley JW. Diabetic peripheral neuropathy: evidence for apoptosis and associated mitochondrial dysfunction. Diabetes. 2000; 49:1932-8. [PubMed: 11078462]

43. Guo C, Quobatari A, Shangguan Y, et al. Diabetic autonomic neuropathy: evidence for apoptosis in situ in the rat. Neurogastroenterol Motil. 2004; 16:335-45. [PubMed: 15198656]

44. Surendran S, Kondapaka SB. Altered expression of neuronal nitric oxide synthase in the duodenum longitudinal muscle-myenteric plexus of obesity induced diabetes mouse: implications on enteric neurodegeneration. Biochem Biophys Res Commun. 2005; 338:919-22. [PubMed: 16256069]

45. Jackson MW, Gordon TP, Waterman SA. Disruption of intestinal motility by a calcium channelstimulating autoantibody in type 1 diabetes. Gastroenterology. 2004; 126:819-28. [PubMed: 14988836]

46. Srinivasan S, Stevens MJ, Sheng H, et al. Serum from patients with type 2 diabetes with neuropathy induces complement-independent, calcium-dependent apoptosis in cultured neuronal cells. J Clin Invest. 1998; 102:1454-62. [PubMed: 9769338]

47. Giron MD, Salto R, Gonzalez Y, et al. Modulation of hepatic and intestinal glutathione Stransferases and other antioxidant enzymes by dietary lipids in streptozotocin diabetic rats. Chemosphere. 1999; 38:3003-13. [PubMed: 10230044]

48. Bhor VM, Raghuram N, Sivakami S. Oxidative damage and altered antioxidant enzyme activities in the small intestine of streptozotocin-induced diabetic rats. Int J Biochem Cell Biol. 2004; 36:89-97. [PubMed: 14592535]

49. Semra YK, Wang M, Peat NJ, et al. Selective susceptibility of different populations of sympathetic neurons to diabetic neuropathy in vivo is reflected by increased vulnerability to oxidative stress in vitro. Neurosci Lett. 2006; 407:199-204. [PubMed: 16973273]

50. Carroll SL, Byer SJ, Dorsey DA, et al. Ganglion-specific patterns of diabetes-modulated gene expression are established in prevertebral and paravertebral sympathetic ganglia prior to the development of neuroaxonal dystrophy. J Neuropathol Exp Neurol. 2004; 63:1144-54. [PubMed: 15581182]

51. Vincent AM, Perrone L, Sullivan KA, et al. Receptor for advanced glycation end products activation injures primary sensory neurons via oxidative stress. Endocrinology. 2007; 148:548-58. [PubMed: 17095586]

52. Korenaga K, Micci MA, Taglialatela G, et al. Suppression of nNOS expression in rat enteric neurones by the receptor for advanced glycation end-products. Neurogastroenterol Motil. 2006; 18:392-400. [PubMed: 16629867]

53. Scott JN, Clark AW, Zochodne DW. Neurofilament and tubulin gene expression in progressive experimental diabetes: failure of synthesis and export by sensory neurons. Brain. 1999; 122(Pt 11): 2109-18. [PubMed: 10545396] 
54. Schmidt RE, Dorsey DA, Beaudet LN, et al. Effect of IGF-I and neurotrophin-3 on gracile neuroaxonal dystrophy in diabetic and aging rats. Brain Res. 2000; 876:88-94. [PubMed: 10973596]

55. Calcutt NA, Allendoerfer KL, Mizisin AP, et al. Therapeutic efficacy of sonic hedgehog protein in experimental diabetic neuropathy. J Clin Invest. 2003; 111:507-14. [PubMed: 12588889]

56. Shotton HR, Broadbent S, Lincoln J. Prevention and partial reversal of diabetes-induced changes in enteric nerves of the rat ileum by combined treatment with alpha-lipoic acid and evening primrose oil. Auton Neurosci. 2004; 111:57-65. [PubMed: 15109939]

57. Nowak TV, Harrington B, Weisbruch JP, et al. Structural and functional characteristics of muscle from diabetic rodent small intestine. Am J Physiol. 1990; 258(5 Pt 1):G690-8. [PubMed: 2185667]

58. Carrier GO, Aronstam RS. Increased muscarinic responsiveness and decreased muscarinic receptor content in ileal smooth muscle in diabetes. J Pharmacol Exp Ther. 1990; 254:445-9. [PubMed: 2384882]

59. Soulie ML, Cros G, Serrano JJ, et al. Impairment of contractile response to carbachol and muscarinic receptor coupling in gastric antral smooth muscle cells isolated from diabetic streptozotocin-treated rats and db/db mice. Mol Cell Biochem. 1992; 109:185-8. [PubMed: 1385642]

60. Takahashi T, Kojima Y, Tsunoda Y, et al. Impaired intra-cellular signal transduction in gastric smooth muscle of diabetic BB/W rats. Am J Physiol. 1996; 270(3 Pt 1):G411-7. [PubMed: 8638706]

61. Coulson FR, Jacoby DB, Fryer AD. Insulin regulates neuronal M2 muscarinic receptor function in the ileum of diabetic rats. J Pharmacol Exp Ther. 2004; 308:760-6. [PubMed: 14610235]

62. Horvath VJ, Vittal H, Lorincz A, et al. Reduced stem cell factor links smooth myopathy and loss of interstitial cells of cajal in murine diabetic gastroparesis. Gastroenterology. 2006; 130:759-70. [PubMed: 16530517]

63. Gaddipati KV, Simonian HP, Kresge KM, et al. Abnormal ghrelin and pancreatic polypeptide responses in gastroparesis. Dig Dis Sci. 2006; 51:1339-46. [PubMed: 16868831]

64. Takehara K, Tashima K, Kato S, et al. Failure of the nitric oxide synthase inhibitor to stimulate duodenal bicarbonate secretion in streptozotocin-diabetic rats. Life Sci. 1997; 60:1505-14. [PubMed: 9126871]

65. Tougas G, Hunt RH, Fitzpatrick D, et al. Evidence of impaired afferent vagal function in patients with diabetes gastroparesis. Pacing Clin Electrophysiol. 1992; 15(10 Pt 2):1597-602. [PubMed: 1383975]

66. Aitchison M, Fisher BM, Carter K, et al. Impaired anal sensation and early diabetic faecal incontinence. Diabet Med. 1991; 8:960-3. [PubMed: 1838049]

67. Yagihashi S, Sima AA. Diabetic autonomic neuropathy in BB rat. Ultrastructural and morphometric changes in parasympathetic nerves. Diabetes. 1986; 35:733-43. [PubMed: 3721060]

68. Kniel PC, Junker U, Perrin IV, et al. Varied effects of experimental diabetes on the autonomic nervous system of the rat. Lab Invest. 1986; 54:523-30. [PubMed: 3702343]

69. Schmidt RE, Dorsey DA, Beaudet LN, et al. Non-obese diabetic mice rapidly develop dramatic sympathetic neuritic dystrophy: a new experimental model of diabetic autonomic neuropathy. Am J Pathol. 2003; 163:2077-91. [PubMed: 14578206]

70. Bour-Jordan H, Bluestone JA. Sensory neurons link the nervous system and autoimmune diabetes. Cell. 2006; 127:1097-9. [PubMed: 17174888]

71. Wheway J, Mackay CR, Newton RA, et al. A fundamental bimodal role for neuropeptide Y1 receptor in the immune system. J Exp Med. 2005; 202:1527-38. [PubMed: 16330815]

72. McGillis JP, Humphreys S, Reid S. Characterization of functional calcitonin gene-related peptide receptors on rat lymphocytes. J Immunol. 1991; 147:3482-9. [PubMed: 1719079]

73. Gutierrez-Canas I, Juarranz Y, Santiago B, et al. VIP down-regulates TLR4 expression and TLR4mediated chemokine production in human rheumatoid synovial fibroblasts. Rheumatology (Oxford). 2006; 45:527-32. [PubMed: 16319097] 
74. Belai A, Lincoln J, Burnstock G. Lack of release of vasoactive intestinal polypeptide and calcitonin gene-related peptide during electrical stimulation of enteric nerves in streptozotocindiabetic rats. Gastroenterology. 1987; 93:1034-40. [PubMed: 2443415]

75. Belai A, Burnstock G. Changes in adrenergic and peptidergic nerves in the submucous plexus of streptozocin-diabetic rat ileum. Gastroenterology. 1990; 98:1427-36. [PubMed: 1692544]

76. Schmidt RE, Plurad DA, Roth KA. Effects of chronic experimental streptozotocin-induced diabetes on the nor-adrenergic and peptidergic innervation of the rat alimentary tract. Brain Res. 1988; 458:353-60. [PubMed: 2905198] 


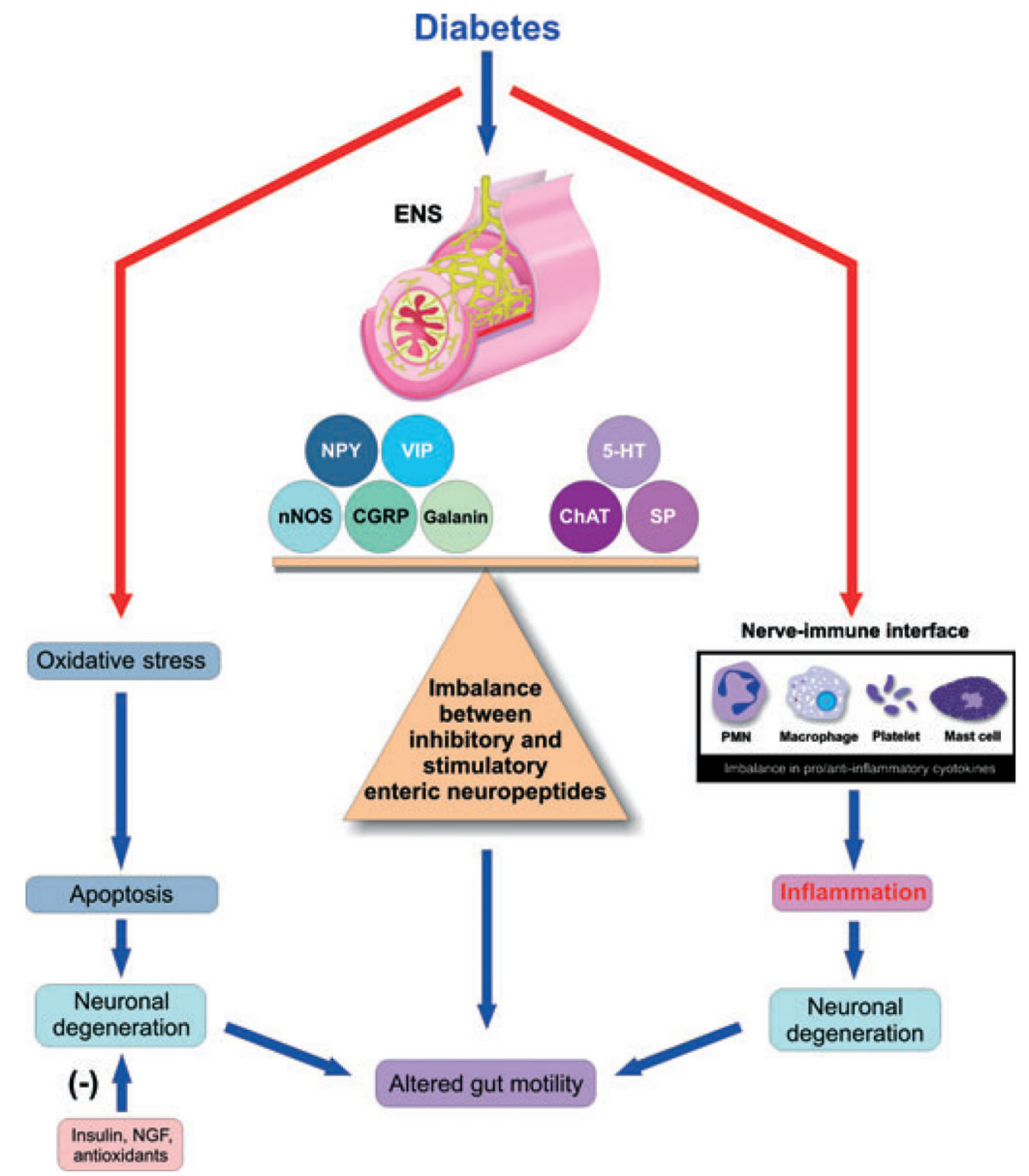

Figure 1.

Schematic representation of the central role of enteric neuropeptides in diabetes: diabetes leads to an imbalance of inhibitory and excitatory neuropeptide ratios which can directly cause altered gut motility. In addition, hyperglycaemia can also cause oxidative stress and apoptosis. Other potential mechanisms involve the role of neuropeptides from enteric nervous system (ENS) interacting with immune cells and activating pro-inflammatory cytokine production leading to inflammation and subsequent neuronal loss. Thus oxidative stress, apoptosis and inflammation cause nerve damage leading to gastrointestinal motility disturbances. 


\section{Table 1}

Diabetes induced changes in neuronal number in the gastrointestinal tract

\begin{tabular}{|c|c|c|c|}
\hline Duration of diabetes (weeks) & Location of change & Type of change & References \\
\hline 1 & Proximal colon & $\downarrow$ NADPH diaphorase & Furlan et al. ${ }^{7}$ \\
\hline 2 & Auerbach's plexus & Degeneration of axolemma, chromatolysis of ganglion & Monckton \& Pehowich ${ }^{3}$ \\
\hline 8 & Stomach & $\downarrow$ NADPH diaphorase & Fregonesi et al. ${ }^{4}$ \\
\hline 8 & Cecum-myenteric & $\downarrow$ Neuronal density & Zanoni et $a l^{5}$ \\
\hline 15 & Ileum & $\downarrow$ NADPH diaphorase & Alves et al. ${ }^{6}$ \\
\hline 15 & Jejunum-myenteric & $\uparrow$ Cell body area, $\downarrow$ NADPH diaphorase & De Miranda et al. ${ }^{10}$ \\
\hline 16 & Ileum & $\uparrow \mathrm{NADPH}$ diaphorase & Zanoni et al. ${ }^{9}$ \\
\hline
\end{tabular}




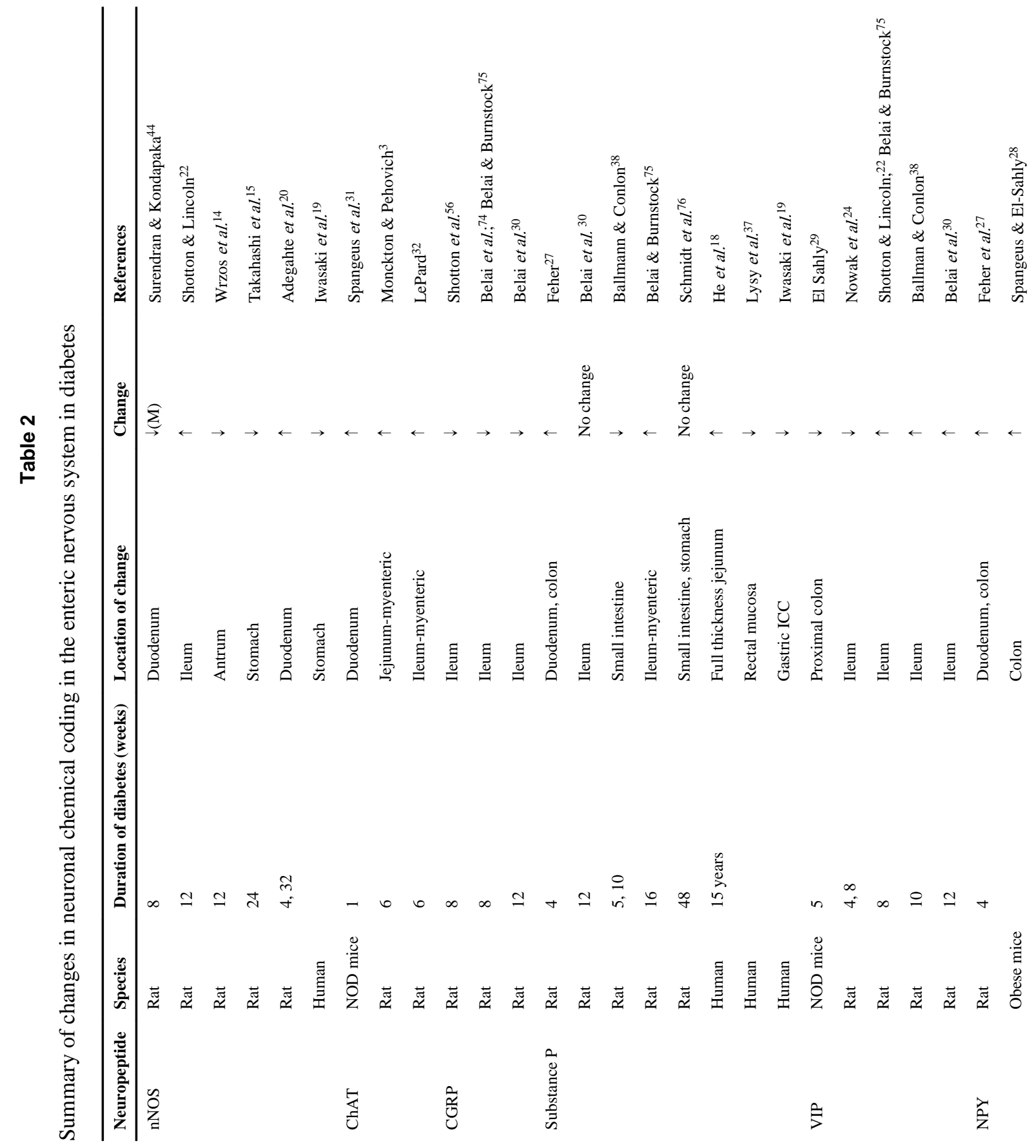

Neurogastroenterol Motil. Author manuscript; available in PMC 2013 July 15. 


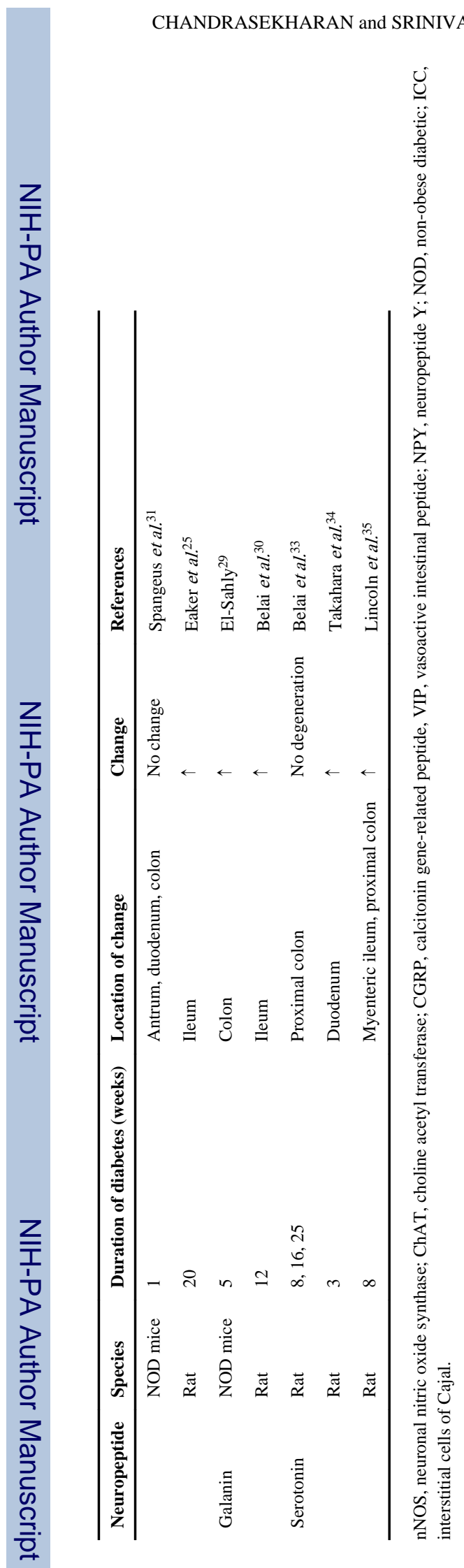

Page 15 